\title{
A meta-analysis of front-line therapy of osimertinib in treating non-small cell lung cancer
}

\author{
Qian $\mathrm{ZHAO}^{1}$, Yunfeng $\mathrm{CHEN}^{1 *}$ (D)
}

\begin{abstract}
Our meta-analysis was designed to explored the efficacy and safety of osimertinib as front-line strategy in advanced non-small-cell lung cancer (NSCLC) whose tumors had sensitive EGFR mutations. Computerized search for trials from CENTRAL, PubMed, Cochrane and EMBASE up to May, 2021. The investigated trials include investigated osimertinib in untreated NSCLC patients with EGFR-mutation. Our meta-analysis summarized the outcomes from 4 studies. Outcomes of this study revealed that PFS was significantly longer for patients treated with osimertinib than the standard EGFR-TKIs/placebo group. In terms of the PFS subgroup analyses, better PFS were found to be higher in patients treated with Osimertinib, regardless of the sex, EGFR-mutated status, and smoking history. Besides, osimertinib improved CNS efficacy in untreated NSCLC patients with EGFR-mutation. In terms of the treatment-related AE subgroup analyses, no difference was identified when comparing Osimertinib vs. the comparable group $(p>0.05)$. The results suggested that First-line osimertinib treatment achieved a clinically meaningful PFS benefit and tolerable AEs for treatment of advanced NSCLC patients with EGFR-mutated than the prior EGFR-TKI/placebo. Meanwhile, osimertinib seemed to be a better option for advanced patients with CNS metastases. In terms of efficacy and tolerability, osimertinib seemed to be a more appropriate upfront therapy among EGFR-mutant NSCLC.
\end{abstract}

Keywords: NSCLC; tumors; EGFR-mutation; osimertinib; CNS metastases.

Practical Application: Further trials exploring sequential strategy of osimertinib and early generation TKIs are needed to provide much more appropriate clinical guidance.

\section{Introduction}

Non-small-cell lung cancer (NSCLC) is the main causes of mortality related to the cancer in the world (Bray et al., 2018; Wang et al., 2021). Largely patients are diagnosed at advanced, and metastatic stage, often asscociated with poor survival and difficult-to-manage disease (Ettinger et al., 2012; Wood et al., 2018; Periyanaina et al., 2020). The activation of epidermal growth factor receptor (EGFR) mutations, like exon 19 deletions (Ex19del) and exon 21 codon p.Leu858Arg (L858R) point mutations, have been found as common oncogenic drivers for NSCLC (Steuer et al., 2015).

EGFR tyrosine kinase inhibitors (EGFR-TKIs) are a group of drugs that block the growth of cancer cells through targeting the EGFR mutation (Sundaresan et al., 2016). Previous clinical studies have provided robust evidence supporting EGFR-TKIs achieve significant clinical benefit compared with chemotherapy. And EGFR-TKIs have been recommended as the first-line therapy for advanced NSCLC with sensitive EGFR mutations (Hanna et al., 2017; Planchard et al., 2018; Wu et al., 2019).

Osimertinib, a third-generation irreversible oral EGFR TKI, potently and selectively inhibits both EGFR-TKI-sensitizing mutations (EGFRm; exon 19 and 21 mutations) and the T790M resistance mutation and shows a promising prognosis on CNS metastases (Wu et al., 2019; Reungwetwattana et al., 2018; Mok et al., 2017).

Based on the FLAURA study, Osimertinib was superior to comparator generation TKIs with respect to significantly longer survival rate in the first-line treatment setting. These findings provided support for osimertinib as the upfront therapy for advanced NSCLC harboring EGFR mutation- positive (Ex19del or L858R) (Soria et al., 2018; Ramalingam et al., 2020). Osimertinib has recently been accepted as a first-line option by the FDA for advanced NSCLC with EGFRm (European Medicine Agencies, 2021; Food and Drug Administration, 2015)

Moreover,the efficacy of EGFR-TKIs led to investigation of their use as an adjuvant treatment for resectable disease. The ADAURA trial have demonstrated that disease-free survival was significantly longer among those patients harboring resected EGFR mutation-positive NSCLC who treated with osimertinib than placebo (Wu et al., 2019).

Thus, the assessment of optimal treatments that may provide promising disease control is a significant clinical priority. We therefore conducted a meta-analysis to analysis the efficacy and safety of osimertinib as front-line therapy in NSCLC that harbored sensitive EGFR mutations. 


\section{Methods and materials}

\subsection{Search strategy}

Published trials about the effectiveness followed by osimertinib in treating untreated patients with NSCLC were retrieved. The PubMed, Embase, Cochrane library were searched till May, 2021. The main search terms and Medical Subject Heading (MeSH) were: "osimertinib" "AZD9291" "EGFR-TKI," "untreated" "firstline" and "non-small cell lung cancer." In addition, two reviewers hand-searched the relevant reference of eligible researches for additional studies.

\subsection{Eligibility criteria}

The eligible trials should met the following criteria: (1) the trials were assigned to analysis the efficacy and safety of osimertinib compared with other EGFR-TKI or chemotherapy or placebo in treating NSCLC; (2) Randomized clinical trials (RCTs) were only included; (3) trials that included participants were untreated NSCLC; (4) the interested results were the progression-free survival (PFS) and toxicity; (5) the trials should provide complete data.

\subsection{Quality assessment}

Two authors rated the quality of the included trials in separate. For randomized studies, the quality was assessed based on the Cochrane Collaboration's "Risk of bias" tool to rate the quality of study.

\subsection{Data extraction}

Data were extracted independently based on predefined eligibility criteria by two researchers. Disagreement was revolved by a third investigator. We extracted the contents from each eligible trial: the lead author, publication year, participant size, median age, male size, patients with smoking status, patients with EGFR mutation status (Ex19del or L858R) and the comparator. In addition, the interested outcomes included toxicity and survival rate.

\subsection{Statistical analysis}

The Review Manager Software (RevMan5.3) has been used for statistical analysis. The $\mathrm{I}^{2}$ statistic was used to measure the heterogeneity between-study (Higgins \& Thompson, 2002). If the degree of heterogeneity was not significant ( $\left.\mathrm{p}>0.1, \mathrm{I}^{2} \leq 50 \%\right)$, the fixed-effect model was used. We used the random-effect model if the degree of heterogeneity was significant (Higgins et al., 2003). The hazard ratio (HR) with $95 \%$ confidence intervals (CIs) was extracted. P value less than 0.05 was set as statistical significance.

\section{Results}

\subsection{Search results and studies characteristics}

Totally, 379 studies were initially searched out. 8 publications were assessed in more detail according to the criteria described in the methods, but some did not provide enough detail of interested results. Finally, a total of 4 studies (Wu et al., 2019; Soria et al., 2018; Ohe et al., 2019; Cheng et al., 2021) were finally considered. The search process is described in Figure 1-3 presented the summary of the quality assessment process Table 1.

\subsection{Clinical and methodological heterogeneity}

\section{Pooled analysis of PFS}

Pooled data showed that the untreated patients with osimertinib show a higher PFS rate than those with other treatments $(\mathrm{OR}=0.42$, $95 \% \mathrm{CI}=0.26-0.67, \mathrm{I}^{2}=86 \%, \mathrm{P}=0.0003$ ) (Figure 4).

Subgroups analysis of PFS

\section{Del19 mutation versus L858R mutation}

PFS data were available from three trials. The benefit favoring osimertinib with respect to progress-free survival was found consistently across both Del19 mutation groups $(\mathrm{OR}=0.28,95 \%$ $\left.\mathrm{CI}=0.13-0.62, \mathrm{I}^{2}=88 \%, \mathrm{P}=0.002\right)$ and $\mathrm{L} 858 \mathrm{R}$ mutation groups $\left(\mathrm{OR}=0.48,95 \% \mathrm{CI}=0.32-0.71, \mathrm{I}^{2}=52 \%, \mathrm{P}=0.0003\right)$ (Figure 5).

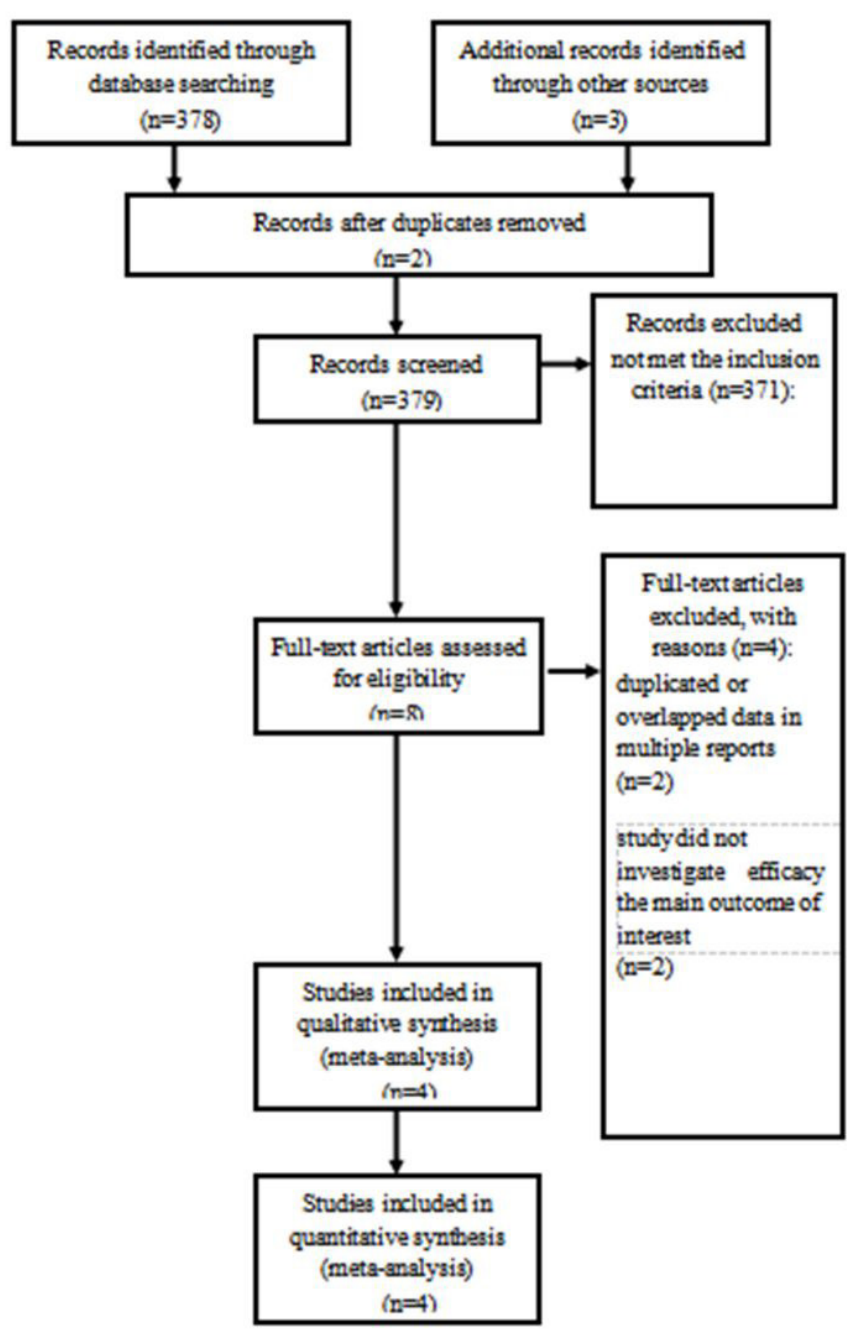

Figure 1. PRISMA flow chart of selection process to identify studies eligible for pooling. 
Patients with CNS metastases

Data for PFS were available from three trials. These results indicated significant difference in reducing risk of CNS progression with osimertinib, when compared with the control group $\left(\mathrm{OR}=0.37,95 \% \mathrm{CI}=0.18-0.77, \mathrm{I}^{2}=78 \%, \mathrm{P}=0.008\right)$ (Figure 6).

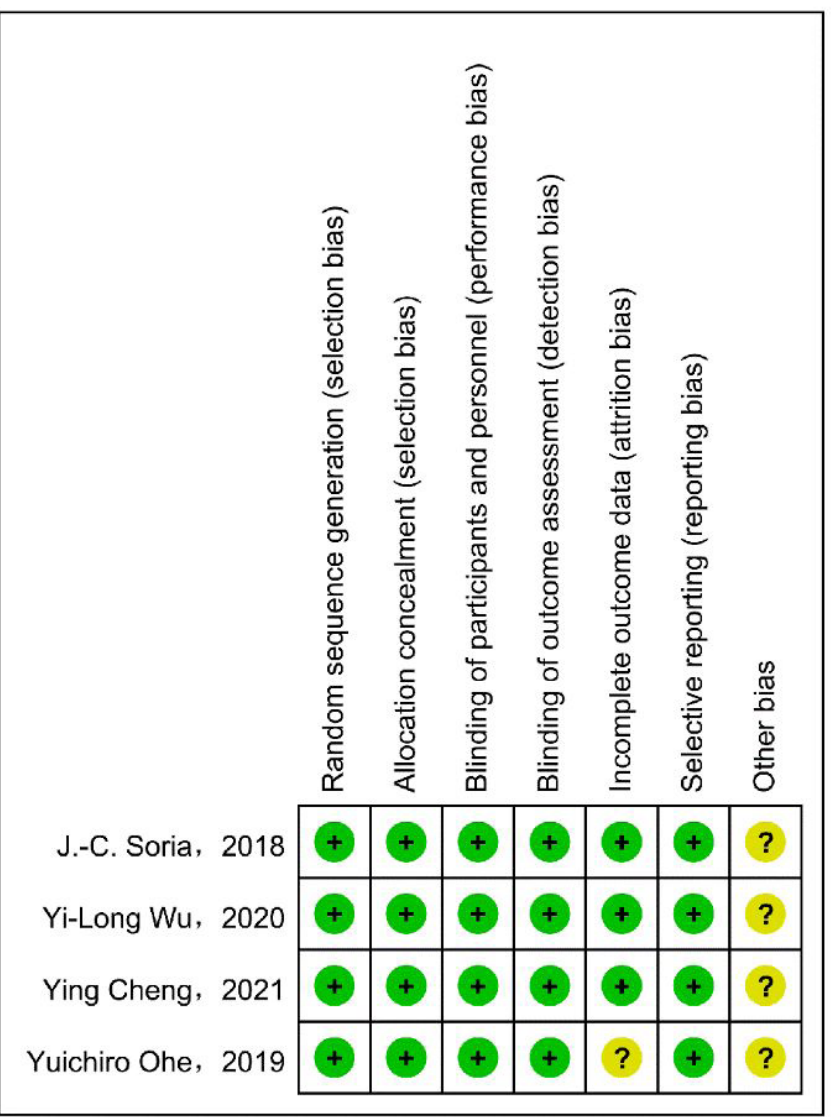

Figure 2. Methodological quality assessment for each included study.
Male versus Female

Results showed that osimertinib performed better than the control group, with statistically significant improvement in PFS for both male $\left(\mathrm{OR}=0.41,95 \% \mathrm{CI}=0.21-0.82, \mathrm{I}^{2}=79 \%\right.$, $\mathrm{P}=0.01)$ and female patients $(\mathrm{OR}=0.33,95 \% \mathrm{CI}=0.19-0.56$, $\mathrm{I}^{2}=78 \%, \mathrm{P}<0.0001$ ) (Figure 7).

Smoking history YES versus NO

The pooled OR was 0.37 (95\% CI: $0.25-0.53$; $\mathrm{I}^{2}=74 \%$, $\mathrm{P}<0.00001$ ), which indicated that osimertinib are better than the control group in respect to the PFS regardless of smoking history (Figure 8).

Pooled analysis of toxicity

Pooled data showed that patients treating with osimertinib favors a comparable toxicity with no statistically significant in all the patients $\left(\mathrm{OR}=1.35,95 \% \mathrm{CI}=0.89-2.05, \mathrm{I}^{2}=73 \%\right.$, $\mathrm{P}=0.15)$, and in subgroup analysis, compared with the control group (Figure 9).

\section{Discussion}

In advanced NSCLC patients harboring an EGFR driver mutation, a highly potent and selective EGFR TKIs should be used as the first-line choice. Currently, all EGFR TKIs are accepted as first-line option (Li et al., 2020). The option of optimal first-line strategy represented actually the optimal sequencing of therapies for the mutant EGFR NSCLC patients (Takeda \& Nakagawa, 2019). The third-generation TKIs following the early-generation TKIs was a reasonable option.

While, relying on the encouraging findings of the FLAURA trial (Soria et al., 2018), the highly efficacy of osimertinib as firstline option has brought a new stage in treatment for advanced NSCLC. Osimertinib, namely AZD9291, has a unique and distinctive chemical structure. Osimertinib harboring a nearly

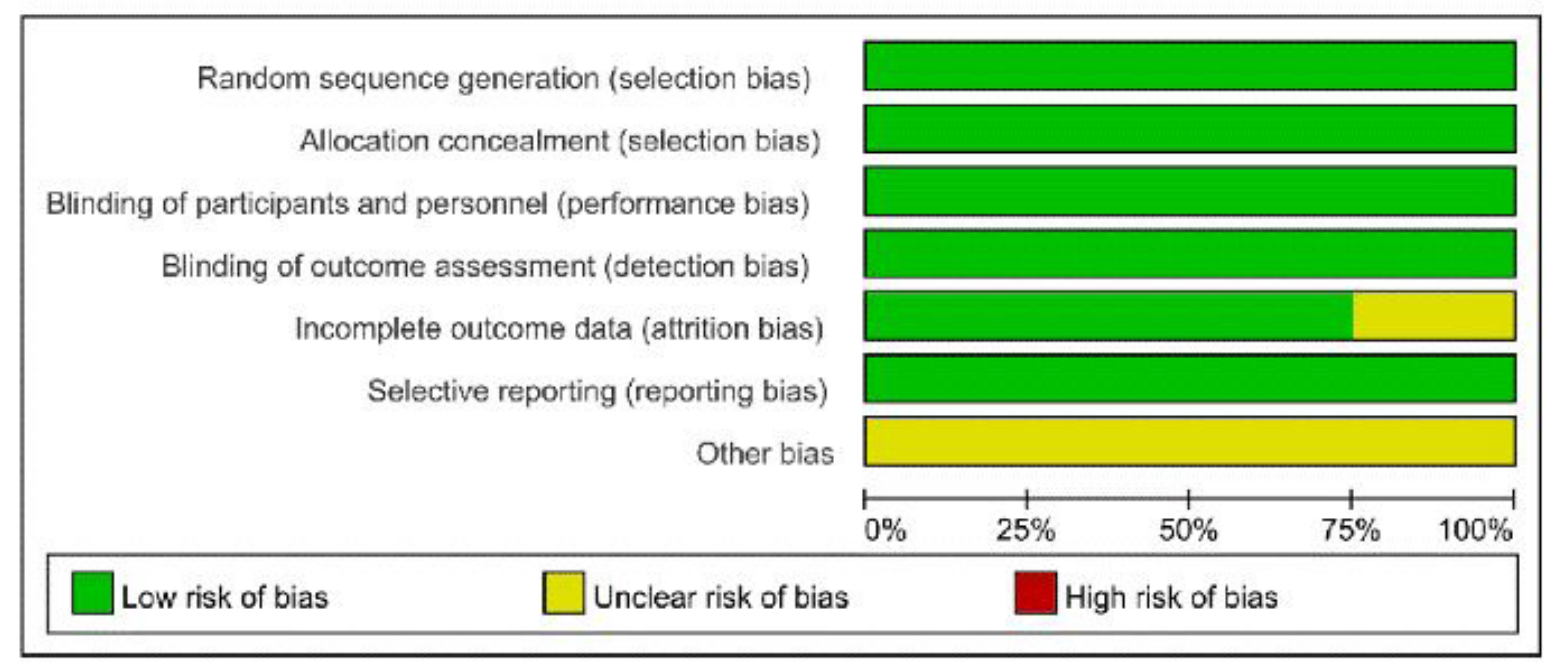

Figure 3. Quality assessment summary for included studies. 
Table 1. The primary characteristics of the eligible studies in more detail.

\begin{tabular}{|c|c|c|c|c|c|c|c|c|c|c|c|c|c|}
\hline \multirow[b]{2}{*}{ Study Year } & \multicolumn{2}{|c|}{ No. of patients } & \multicolumn{2}{|c|}{ Median age } & \multicolumn{2}{|c|}{ Sex(Male) } & \multicolumn{2}{|c|}{ Smoking(Yes) } & \multicolumn{2}{|c|}{$\begin{array}{l}\text { EGFR mutation } \\
\text { type at Ex19del }\end{array}$} & \multicolumn{2}{|c|}{$\begin{array}{c}\text { EGFR mutation } \\
\text { type at L858R }\end{array}$} & \multirow[b]{2}{*}{$\begin{array}{l}\text { EGFR-TKI } \\
\text { comparator }\end{array}$} \\
\hline & 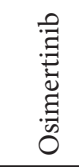 & 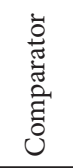 & 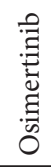 & 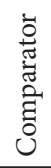 & 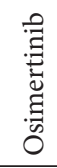 & 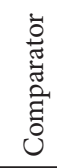 & 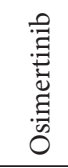 & 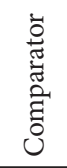 & 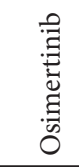 & 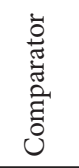 & 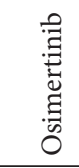 & 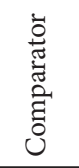 & \\
\hline Soria et al., 2018 & 279 & 277 & 64 & 64 & 101 & 105 & 97 & 102 & 175 & 174 & 104 & 103 & Gefitinib,Erlotinib \\
\hline Ohe et al., 2019 & 65 & 55 & 67 & 67 & 22 & 27 & 35 & 29 & 33 & 30 & 32 & 25 & Gefitinib \\
\hline Cheng et al., 2021 & 71 & 65 & 60 & 61 & 28 & 19 & 18 & 15 & 36 & 33 & 35 & 33 & Gefitinib,Erlotinib \\
\hline Wu et al., 2019 & 339 & 343 & 64 & 62 & 108 & 96 & 108 & 86 & 186 & 188 & 152 & 154 & placebo \\
\hline
\end{tabular}

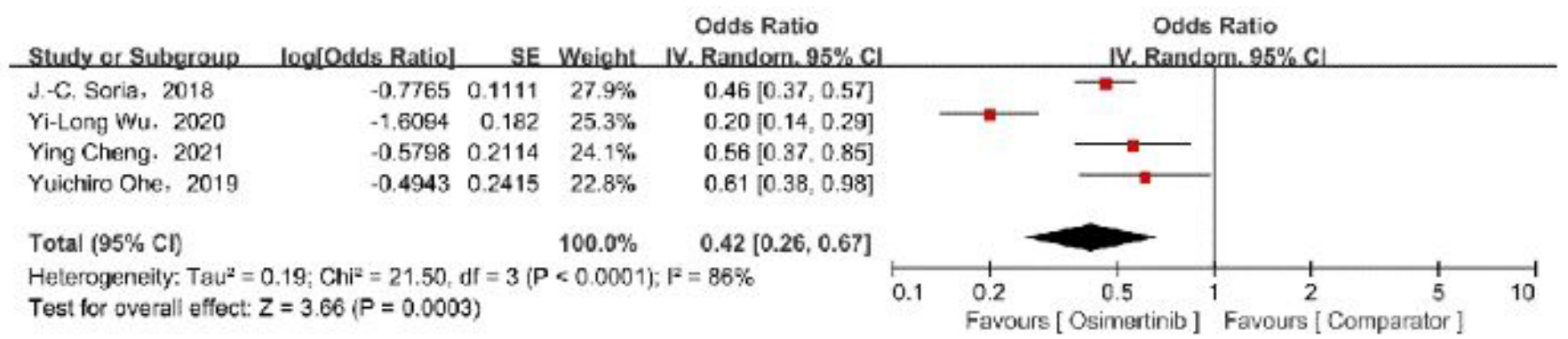

Figure 4. Pooled analysis of PFS.

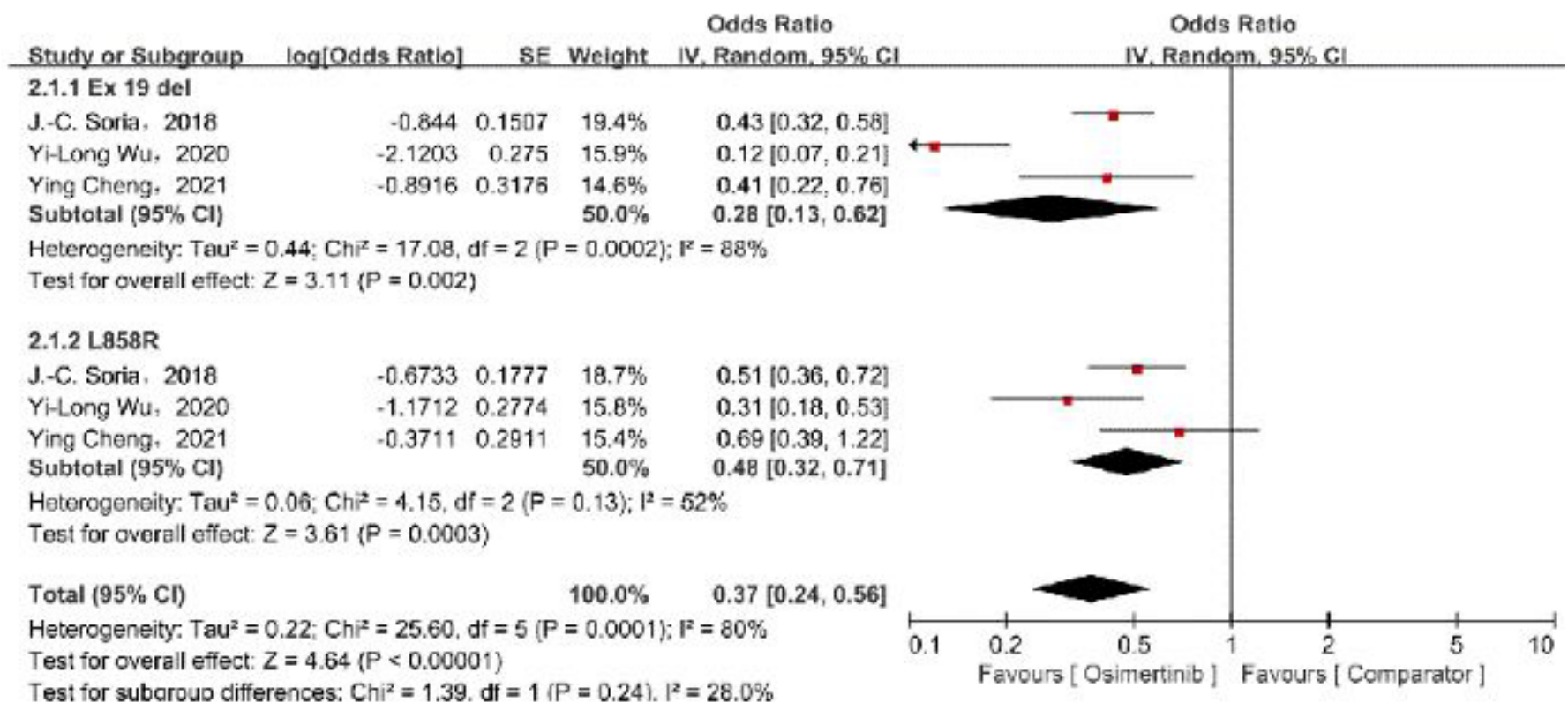

Figure 5. Subgroup analysis of the PFS in terms of the EGFR mutations.

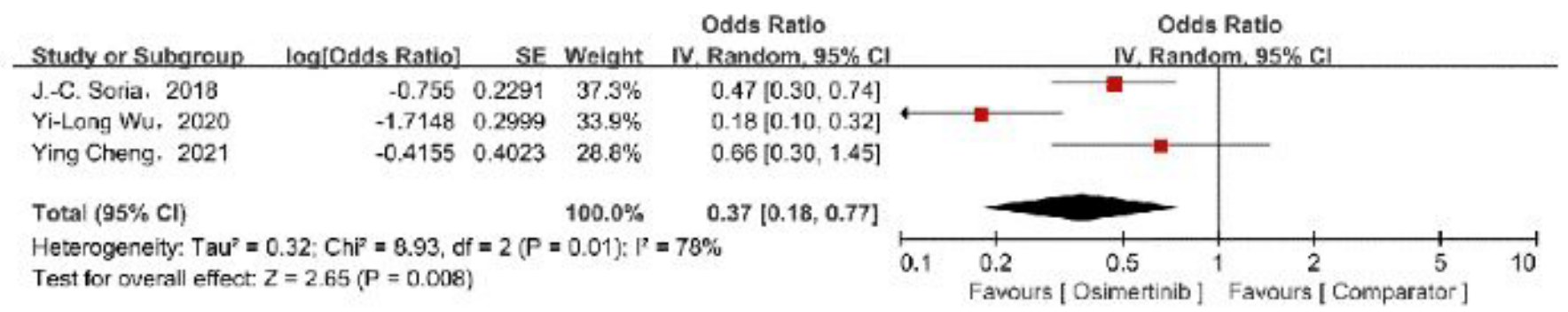

Figure 6. Subgroup analysis of the PFS in terms of the CNS metastases. 


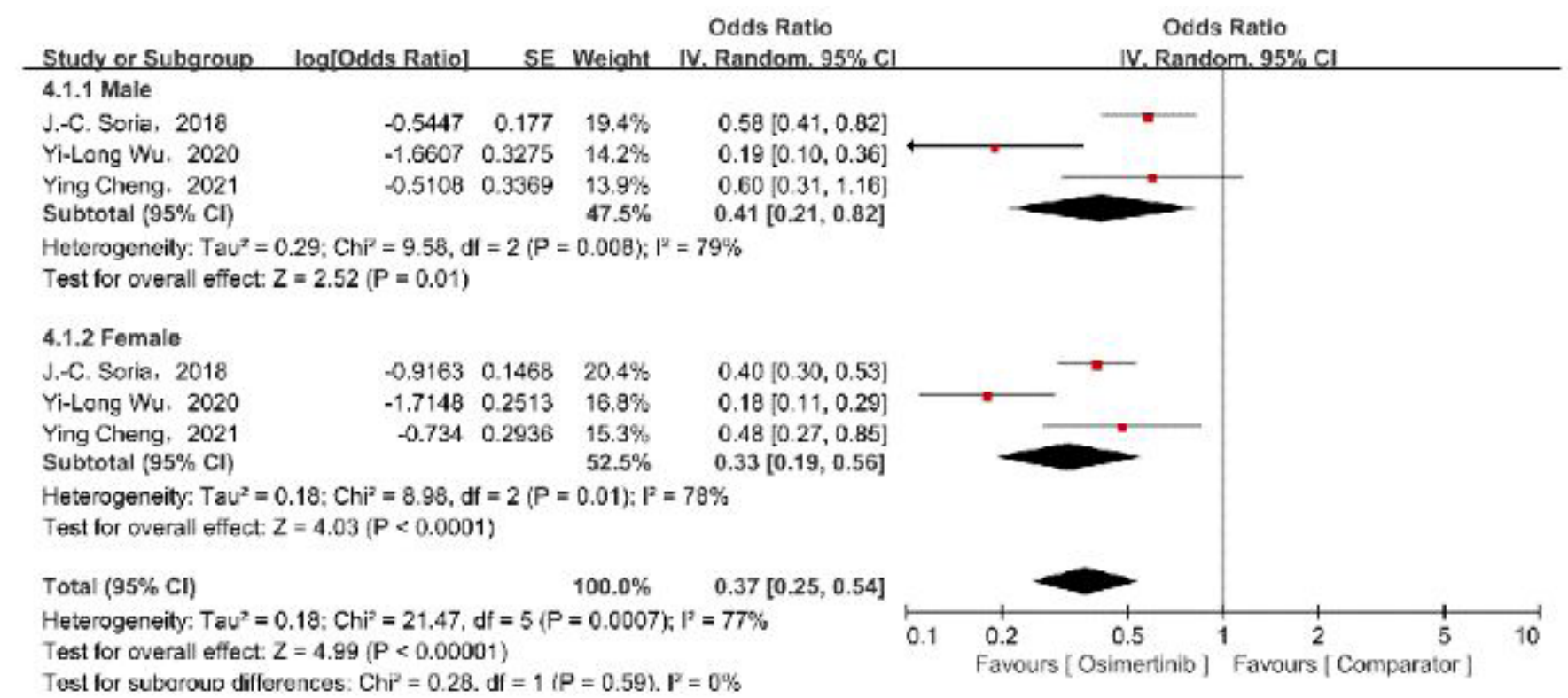

Figure 7. Subgroup analysis of the PFS in terms of the sex.

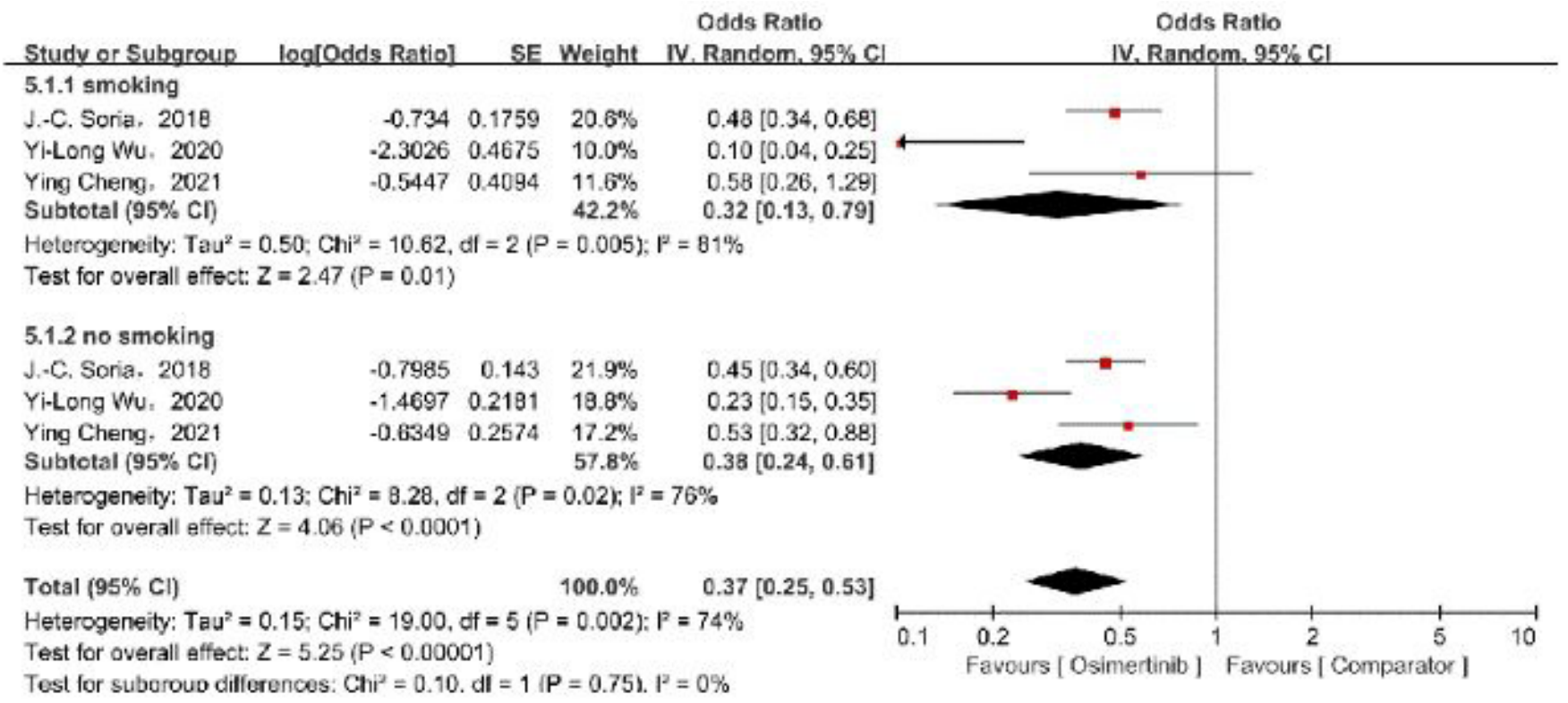

Figure 8. Subgroup analysis of the PFS in terms of the smoking history.

200-fold potency in resistance to L858R/ T790M, which validated its selectivity to the EGFR-mutated NSCLC (Cross et al., 2014)

Previous preclinical studies in vitro models aiming to assess the specificity of various EGFR TKI mutations indicated that osimertinib has shown a full therapeutic window of resistance to EGFR T790M mutations (Hirano et al., 2015; Balthazar et al., 2021; Rafiq et al., 2020, 2021). It has been shown to induce a sustained and profound effect in EGFR-mt tumor xenograft and transgenic models (Cross et al., 2014; Shi et al., 2019;), and to have higher potency against mutant EGFR than first-generation TKI.

Our study is a systematic review to evaluate the efficiencies of osimertinib in treating untreated mutant EGFR NSCLC patients. The results are further confirmed that osimertinib has a superior PFS over standard EGFR-TKIs/placebo as the front-line treatment. The PFS benefit was consistent across all predefined subgroups, regardless of the sex, EGFR-mutated status, and smoking history.

Known to clinician, the CNS is a common site of metastasis in NSCLC, and this metastasis associated with a poor survival (Peters et al., 2016). In terms of the efficacy in CNS metastases, a clinically meaningful PFS benefit was also noted with Osimertinib. This finding is accord with CNS benefit in the global FLAURA study and ADAURA trial. The mechanisms under the result can be due to markedly penetration of blood-brain barrier (BBB) 


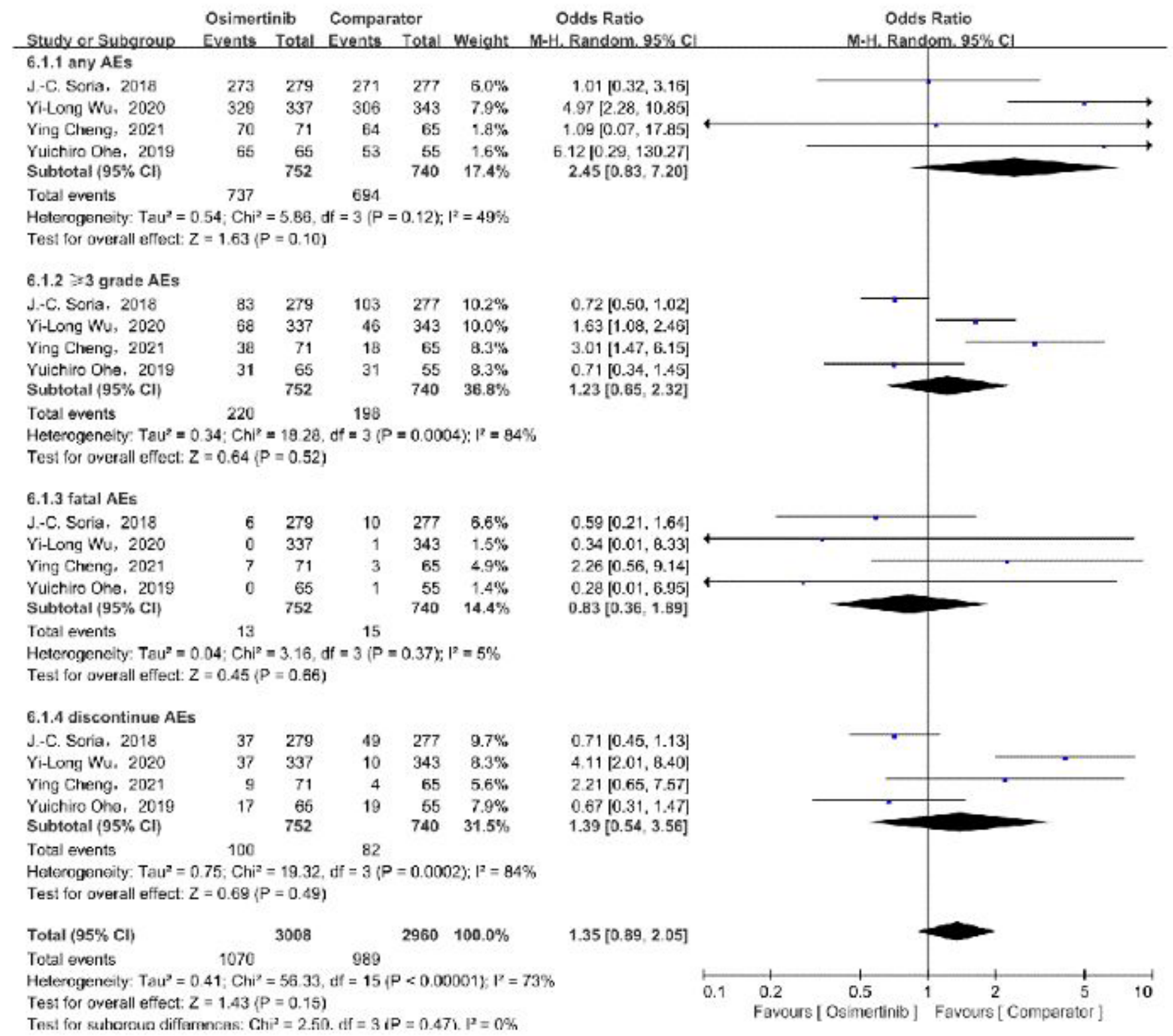

Figure 9. Pooled analysis of adverse effects (AEs).

and durable shrinkage in mouse and nonhuman primate brain models with osimertinib (Ballard et al., 2016). osimertinib was impressively CNS active.

Beyond efficacy, drug safety should also be considered for the drug assessment.The safety profile in our analysis was consistent with previous trials. osimertinib demonstrated acceptable tolerability compared with the comparator EGFR TKI/placebo group. The safety benefit favored osimertinib across all the subgroups. These evidences provide a strong impetus for further research in the first-line treatment with osimertinib.

Our study also had several limitations. First, the heterogeneity due to the lack of patient-level data cannot be discounted entirely. Second, results of overall survival was based on immature and thus was limited data. Future studies are needed to address the overall survival to Osimertinib.

The superior PFS and comparable safety of osimertinib observed in our meta-analysis indicated that first-line therapy with osimertinib could potentially accepted as the first-rank option for EGFRm NSCLC. Besides, osimertinib also demonstrated a clinically meaningful improvement in PFS efficacy on CNS metastases.

Future studies are needed to update our meta-analysis and investigate a more mature assessment of overall survival.

Moreover, further trials exploring sequential strategy of osimertinib and early generation TKIs are needed to provide much more appropriate clinical guidance. 


\section{Abbreviations}

NSCLC: non-small-cell lung cancer. CI: confidence interval. EGFR: epidermal growth factor receptor. Ex19del: exon 19 deletions. L858R: p.Leu858Arg. EGFR-TKIs: EGFR tyrosine kinase inhibitors. MeSH: Medical Subject Heading. RCTs: Randomized clinical trials. PFS: progression-free survival. HR: hazard ratio. CIs: confidence intervals. BBB: blood-brain barrier.

\section{Ethical approval}

This article does not contain any studies with human participants or animals performed by any of the authors.

\section{Conflict of interest}

There are no potential conflicts of interest to disclose.

\section{Author contributions}

Qian Zhao is resposible for the definition of intellectual content, literature research, clinical studies, experimental studies, data acquisition \& analysis, statistical analysis, manuscript preparation \& editing \& review. Yunfeng Chen is resposible for definition of intellectual content, literature research, clinical studies, experimental studies, data acquisition \& analysis, statistical analysis, manuscript preparation \& editing \& review. All authors read and approved the final manuscript.

\section{References}

Ballard, P., Yates, J. W., Yang, Z., Kim, D. W., Yang, J. C., Cantarini, M., Pickup, K., Jordan, A., Hickey, M., Grist, M., Box, M., Johnström, P., Varnäs, K., Malmquist, J., Thress, K. S., Jänne, P. A., \& Cross, D. (2016). Preclinical comparison of osimertinib with other EGFRTKIs in EGFR-Mutant NSCLC brain metastases models, and early evidence of clinical brain metastases activity. Clinical Cancer Research, 22(20), 5130-5140. http://dx.doi.org/10.1158/1078-0432. CCR-16-0399. PMid:27435396.

Balthazar, C. F., Moura, N., Romualdo, G. R., Rocha, R. S., Pimentel, T. C., Esmerino, E. A., Freitas, M. Q., Santillo, A., Silva, M. C., Barbisan, L. F., Cruz, A. G., \& Albenzio, M. (2021). Synbiotic sheep milk ice cream reduces chemically induced mouse colon carcinogenesis. Journal of Dairy Science, 104(7), 7406-7414. http://dx.doi.org/10.3168/ jds.2020-19979. PMid:33934866.

Bray, F., Ferlay, J., Soerjomataram, I., Siegel, R. L., Torre, L. A., \& Jemal, A. (2018). Global cancer statistics 2018: GLOBOCAN estimates of incidence and mortality worldwide for 36 cancers in 185 countries. CA: A Cancer Journal for Clinicians, 68(6), 394-424. http://dx.doi. org/10.3322/caac.21492. PMid:30207593.

Cheng, Y., He, Y., Li, W., Zhang, H. L., Zhou, Q., Wang, B., Liu, C., Walding, A., Saggese, M., Huang, X., Fan, M., Wang, J., \& Ramalingam, S. S. (2021). Osimertinib versus comparator EGFR TKI as first-line treatment for EGFR-Mutated advanced NSCLC: FLAURA China, a randomized study. Targeted Oncology, 16(2), 165-176. http://dx.doi. org/10.1007/s11523-021-00794-6. PMid:33544337.

Cross, D. A., Ashton, S. E., Ghiorghiu, S., Eberlein, C., Nebhan, C. A., Spitzler, P. J., Orme, J. P., Finlay, M. R., Ward, R. A., Mellor, M. J., Hughes, G., Rahi, A., Jacobs, V. N., Brewer, M. R., Ichihara, E., Sun, J., Jin, H., Ballard, P., Al-Kadhimi, K., Rowlinson, R., Klinowska, T., Richmond, G. H., Cantarini, M., Kim, D. W., Ranson, M. R., \& Pao, W. (2014). AZD9291, an irreversible EGFR TKI, overcomes
T790M-mediated resistance to EGFR inhibitors in lung cancer. Cancer Discovery, 4(9), 1046-1061. http://dx.doi.org/10.1158/21598290.CD-14-0337. PMid:24893891.

Ettinger, D. S., Akerley, W., Borghaei, H., Chang, A. C., Cheney, R. T., Chirieac, L. R., D’Amico, T. A., Demmy, T. L., Ganti, A. K., Govindan, R., Grannis, F. W. Jr., Horn, L., Jahan, T. M., Jahanzeb, M., Kessinger, A., Komaki, R., Kong, F. M., Kris, M. G., Krug, L. M., Lennes, I. T., Loo, B. W. Jr., Martins, R., O’Malley, J., Osarogiagbon, R. U., Otterson, G. A., Patel, J. D., Pinder-Schenck, M. C., Pisters, K. M., Reckamp, K., Riely, G. J., Rohren, E., Swanson, S. J., Wood, D. E., Yang, S. C., Hughes, M., \& Gregory, K. M. (2012). Non-small cell lung cancer. Journal of the National Comprehensive Cancer Network, 10(10), 12361271. http://dx.doi.org/10.6004/jnccn.2012.0130. PMid:23054877.

European Medicine Agencies - EMA. (2021). Annex I. Summary of product characteristics (Tagrisso (osimertinib)). Amsterdam: EPAR.

Food and Drug Administration - FDA. (2015). Highlights of prescribing information (Tagrisso (osimertinib)). Pooks Hill: FDA.

Hanna, N., Johnson, D., Temin, S., Baker, S. Jr., Brahmer, J., Ellis, P. M., Giaccone, G., Hesketh, P. J., Jaiyesimi, I., Leighl, N. B., Riely, G. J., Schiller, J. H., Schneider, B. J., Smith, T. J., Tashbar, J., Biermann, W. A., \& Masters, G. (2017). Systemic therapy for stage IV non-small-cell lung cancer: American Society of Clinical Oncology clinical practice guideline update. Journal of Clinical Oncology, 35(30), 3484-3515. http://dx.doi.org/10.1200/JCO.2017.74.6065. PMid:28806116.

Higgins, J. P., \& Thompson, S. G. (2002). Quantifying heterogeneity in a meta-analysis. Statistics in Medicine, 21(11), 1539-1558. http:// dx.doi.org/10.1002/sim.1186. PMid:12111919.

Higgins, J. P., Thompson, S. G., Deeks, J. J., \& Altman, D. G. (2003). Measuring inconsistency in meta-analyses. The BMJ, 327(7414), 557560. http://dx.doi.org/10.1136/bmj.327.7414.557. PMid:12958120.

Hirano, T., Yasuda, H., Tani, T., Hamamoto, J., Oashi, A., Ishioka, K., Arai, D., Nukaga, S., Miyawaki, M., Kawada, I., Naoki, K., Costa, D. B., Kobayashi, S. S., Betsuyaku, T., \& Soejima, K. (2015). In vitro modeling to determine mutation specificity of EGFR tyrosine kinase inhibitors against clinically relevant EGFR mutants in non-smallcell lung cancer. Oncotarget, 6(36), 38789-38803. http://dx.doi. org/10.18632/oncotarget.5887. PMid:26515464.

Li, X. Y., Lin, J. Z., \& Yu, S. H. (2020). Front-line therapy in advanced non-small cell lung cancer with sensitive epidermal growth factor receptor mutations: a network meta-analysis. Clinical Therapeutics, 42(2), 338-350. http://dx.doi.org/10.1016/j.clinthera.2019.12.006. PMid:31937461.

Mok, T. S., Wu, Y., Ahn, M., Garassino, M. C., Kim, H. R., Ramalingam, S. S., Shepherd, F. A., He, Y., Akamatsu, H., Theelen, W. S., Lee, C. K., Sebastian, M., Templeton, A., Mann, H., Marotti, M., Ghiorghiu, S., \& Papadimitrakopoulou, V. A. (2017). Osimertinib or platinumpemetrexed in EGFR T790M-positive lung cancer. The New England Journal of Medicine, 376(7), 629-640. http://dx.doi.org/10.1056/ NEJMoa1612674. PMid:27959700.

Ohe, Y., Imamura, F., Nogami, N., Okamoto, I., Kurata, T., Kato, T., Sugawara, S., Ramalingam, S. S., Uchida, H., Hodge, R., Vowler, S. L., Walding, A., \& Nakagawa, K. (2019). Osimertinib versus standard-of-care EGFR-TKI as first-line treatment for EGFRm advanced NSCLC: FLAURA Japanese subset. Japanese Journal of Clinical Oncology, 49(1), 29-36. http://dx.doi.org/10.1093/jjco/ hyy179. PMid:30508196.

Periyanaina, K., Sundaramsivamaruthi, B., \& Chaiyavat, C. (2020). Health promoting effects of fermented foods against cancer: an updated concise review. Food Science and Technology, [Ahead of print].

Peters, S., Bexelius, C., Munk, V., \& Leighl, N. (2016). The impact of brain metastasis on quality of life, resource utilization and survival 
in patients with non-small-cell lung cancer. Cancer Treatment Reviews, 45, 139-162. http://dx.doi.org/10.1016/j.ctrv.2016.03.009. PMid:27019457.

Planchard, D., Popat, S., Kerr, K., Novello, S., Smit, E. F., Faivre-Finn, C., Mok, T. S., Reck, M., Van Schil, P. E., Hellmann, M. D., \& Peters, S. (2018). Metastatic non-small cell lung cancer: ESMO Clinical Practice Guidlines for diagnosis, treatment and follow-up. Annals of Oncology, 29(Suppl. 4), IV192-IV237. http://dx.doi.org/10.1093/ annonc/mdy275.

Rafiq, S., Gulzar, N., Huma, N., Hussain, I., Murtaza, M. A. (2020) Evaluation of anti-proliferative activity of Cheddar cheeses using colon adenocarcinoma (HCT-116) cell line. International Journal of Dairy Technology, 73(1), 255-260.

Rafiq, S., Gulzar, N., Sameen, A., Huma, N., Hayat, I., Ijaz, R. (2021). Functional role of bioactive peptides with special reference to cheeses. International Journal of Dairy Technology, 74(1), 1-16.

Ramalingam, S. S., Vansteenkiste, J., Planchard, D., Cho, B. C., Gray, J. E., Ohe, Y., Zhou, C., Reungwetwattana, T., Cheng, Y., Chewaskulyong, B., Shah, R., Cobo, M., Lee, K. H., Cheema, P., Tiseo, M., John, T., Lin, M. C., Imamura, F., Kurata, T., Todd, A., Hodge, R., Saggese, M., Rukazenkov, Y., \& Soria, J. C. (2020). Overall survival with Osimertinib in untreated, EGFR-mutated advanced NSCLC. The New England Journal of Medicine, 382(1), 41-50. http://dx.doi. org/10.1056/NEJMoa1913662. PMid:31751012.

Reungwetwattana, T., Nakagawa, K., Cho, B. C., Cobo, M., Cho, E. K., Bertolini, A., Bohnet, S., Zhou, C., Lee, K. H., Nogami, N., Okamoto, I., Leighl, N., Hodge, R., McKeown, A., Brown, A. P., Rukazenkov, Y., Ramalingam, S. S., \& Vansteenkiste, J. (2018). CNS response to Osimertinib versus standard epidermal growth factor receptor Tyrosine Kinase inhibitors in patients with untreated EGFR-mutated advanced non-small-cell lung cancer. Journal of Clinical Oncology, JCO2018783118. http://dx.doi.org/10.1200/JCO.2018.78.3118. PMid:30153097. [Ahead of print].

Shi, P., Zhang, S., Zhu, L., Qian, G., Ren, H., Ramalingam, S. S., Chen, M., \& Sun, S. Y. (2019). The third-generation EGFR inhibitor, Osimertinib, promotes c-FLIP degradation, enhancing apoptosis including TRAIL-induced apoptosis in NSCLC Cells with activating EGFR mutations. Translational Oncology, 12(5), 705-713. http:// dx.doi.org/10.1016/j.tranon.2019.02.006. PMid:30856555.

Soria, J. C., Ohe, Y., Vansteenkiste, J., Reungwetwattana, T., Chewaskulyong, B., Lee, K. H., Dechaphunkul, A., Imamura, F., Nogami, N., Kurata, T., Okamoto, I., Zhou, C., Cho, B. C., Cheng, Y., Cho, E. K., Voon, P. J., Planchard, D., Su, W. C., Gray, J. E., Lee, S. M., Hodge, R., Marotti, M., Rukazenkov, Y., \& Ramalingam, S. S. (2018). Osimertinib in untreated EGFR-mutated advanced non-small-cell lung cancer. The New England Journal of Medicine, 378(2), 113-125. http://dx.doi. org/10.1056/NEJMoa1713137. PMid:29151359.

Steuer, C. E., Khuri, F. R., \& Ramalingam, S. S. (2015). The next generation of epidermal growth factor receptor tyrosine kinase inhibitors in the treatment of lung cancer. Cancer, 121(8), E1-E6. http://dx.doi. org/10.1002/cncr.29139. PMid:25521095.

Sundaresan, T. K., Sequist, L. V., Heymach, J. V., Riely, G. J., Jänne, P. A., Koch, W. H., Sullivan, J. P., Fox, D. B., Maher, R., Muzikansky, A., Webb, A., Tran, H. T., Giri, U., Fleisher, M., Yu, H. A., Wei, W., Johnson, B. E., Barber, T. A., Walsh, J. R., Engelman, J. A., Stott, S. L., Kapur, R., Maheswaran, S., Toner, M., \& Haber, D. A. (2016). Detection of T790M, the Acquired Resistance EGFR mutation, by tumor biopsy versus noninvasive blood-based analyses. Clinical Cancer Research, 22(5), 1103-1110. http://dx.doi.org/10.1158/10780432.CCR-15-1031. PMid:26446944.

Takeda, M., \& Nakagawa, K. (2019). First- and Second-Generation EGFR-TKIs Are all replaced to Osimertinib in chemo-naive EGFR mutation-positive non-small cell lung cancer? International Journal of Molecular Sciences, 20(1), 146. http://dx.doi.org/10.3390/ ijms20010146. PMid:30609789.

Wang, Y., Wang, L., Guo, J., Wang, X. Y., \& Hua, S. C. (2021). The efficacy and safety of endostar combined gemcitabine and cisplatin in the treatment of non-small cell lung cancer: a meta-analysis. Food Science and Technology, [Ahead of print].

Wood, D. E., Kazerooni, E. A., Baum, S. L., Eapen, G. A., Ettinger, D. S., Hou, L., Jackman, D. M., Klippenstein, D., Kumar, R., Lackner, R. P., Leard, L. E., Lennes, I. T., Leung, A. N. C., Makani, S. S., Massion, P. P., Mazzone, P., Merritt, R. E., Meyers, B. F., Midthun, D. E., Pipavath, S., Pratt, C., Reddy, C., Reid, M. E., Rotter, A. J., Sachs, P. B., Schabath, M. B., Schiebler, M. L., Tong, B. C., Travis, W. D., Wei, B., Yang, S. C., Gregory, K. M., \& Hughes, M. (2018). Lung cancer screening, version 3.2018, NCCN clinical practice guidelines in oncology. Journal of the National Comprehensive Cancer Network, 16(4), 412-441. http://dx.doi.org/10.6004/jnccn.2018.0020. PMid:29632061.

Wu, Y. L., Planchard, D., Lu, S., Sun, H., Yamamoto, N., Kim, D. W., Tan, D. S. W., Yang, J. C., Azrif, M., Mitsudomi, T., Park, K., Soo, R. A., Chang, J. W. C., Alip, A., Peters, S., \& Douillard, J. Y. (2019). PanAsian adapted Clinical Practice Guidelines for the management of patients with metastatic non-small-cell lung cancer: a CSCO-ESMO initiative endorsed by JSMO, KSMO, MOS, SSO and TOS. Annals of Oncology, 30(2), 171-210. http://dx.doi.org/10.1093/annonc/ mdy554. PMid:30596843. 